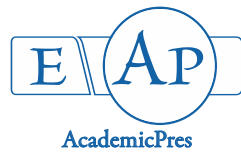

\title{
Canopy Temperature and Chlorophyll Content are Effective Measures of Drought Stress Tolerance in Durum Wheat
}

\author{
Fereshteh JOKAR ${ }^{1}$, Rahmatollah KARIMIZADEH ${ }^{2}$, \\ Asad MASOUMIASL ${ }^{1 *}$, Reza AMIRI FAHLIANI ${ }^{1}$ \\ ${ }^{1}$ Yasouj University, Faculty of Agriculture, Department of Agronomy and Plant Breeding, Yasouj, \\ Iran; Fereshtejokar@gmail.com; masoumiasl@yu.ac.ir ("correspondingauthor);amiri@yu.ac.ir \\ ${ }^{2}$ Education and Extension Organization (AREEO), Dryland Agriculture Research Institute (DARI), Gachsaran, \\ Iran;Karimizadeh_ra@yahoo.com
}

\begin{abstract}
Durum wheat (Triticum durum L.) is used for the preparation of multiple food products, including pasta and bread. Its production is restricted due to diverse environmental stresses i.e. drought and heat stress. Here, comparative analysis of durum wheat varieties was done by studying canopy temperature depression (CTD) and chlorophyll content (CHL), yield and yield contributing traits to evaluate their performance under stress and low stress conditions. Twelve durum wheat genotypes were studied under stressful and low-stress conditions in Gachsaran region of Iran. CTD and CHL were measured at two stages, from the emergence of fifty percent of inflorescence (ZGS 54) to watery ripe stage (ZGS 71). According to stress tolerance index (STI), mean productivity (MP) and geometric mean productivity (GMP) indices, genotype G10 exhibited the most, while genotype G6, the least relative tolerance, respectively. Based on MP and GMP, genotype G10 was found to be drought tolerant, while genotype G2 displayed the lowest amount of MP and GMP. Therefore these genotypes are recommended to be used as genitors in artificial hybridization for improvement of drought tolerance in other cultivars. All indices had high correlation with grain yield under stress and non-stress condition, indicating more suitability of these indices for selection of resistant genotype. Results of the present study showed that among drought tolerance indices, harmonic mean (HM), GMP, CTD and modified STI index (K2STI) can be used as the most suitable indicators for screening drought tolerant cultivars.
\end{abstract}

Keywords: genotype; rain-fed; screening; supplementary irrigation; yield

\section{Introduction}

Wheat is the most important food grain source for humanity with a current global production of 700 million metric tons (FAO, 2015). Durum wheat is one of the most important cereal crops in the world, but grown on only 8 to $10 \%$ of all the wheat-cultivated area (FAO, 2015). Durum wheat is better adapted to semiarid environments compared with bread wheat and is a crop adapted to marginal lands (Karimizadeh et al., 2016a; 2016b).

Increasing the genetic potential of yield in water deficit condition is one of major goals for durum wheat breeding programs in Iran and other countries. Drought tolerance is a polygenic trait and is considered as one of the most important factors limiting crop yields around the world. The response of plants to water stress depends on several factors such as developmental stage, severity and duration of stress and cultivar genetics (Beltrano and Ronco, 2008).
Several selection criteria have been proposed for selecting the best genotypes based on their performance in stress and non-stress environments. Rosielle and Hamblin (1981) showed that lower stress tolerance index (STI) is close to plant resistance to drought stress. Stress tolerance index (STI) was defined by Fernandez (1992) for determining high yield and stress tolerance potential of genotypes. Blum (1988) defined a new index of drought resistance index (DI), which was commonly accepted to find genotypes producing high yield under both stress and non-stress conditions. Rosielle and Hamblin (1981) defined stress tolerance (TOL) as the differences in yield between stress and irrigated environments and mean productivity (MP) as the average yield of genotypes under stress and non-stress conditions. The geometric mean productivity (GMP) is often used by breeders interested in relative performance, since drought stress can vary in severity in field environments over years (Fernandez, 1992). Fischer and Maurer (1978) suggested the stress susceptibility index (SSI) 
576

for measurement of yield stability that apprehended the changes in both potential and real yields in variable environments. Clarke et al. (1992) used SSI to check drought tolerance in wheat genotypes. In spring wheat cultivars, Guttieri et al. (2001) using SSI, suggested that an SSI $>1$ indicated above-average susceptibility to drought stress. The yield index and yield stability index (YSI) was suggested by Bouslama and Schapaugh (1984) to evaluate the stability of genotypes in the both stress and non-stress conditions. To improve the efficiency of STI, a modified stress tolerance index (MSTI) was suggested by Farshadfar and Sutka (2003), which corrects the STI as a weight. Moosavi et al. (2008) introduced stress susceptibility percentage index (SSPI) for screening drought tolerant genotypes.

Breeding for drought tolerance is complicated also by the lack of fast, reproducible screening techniques and the inability to routinely create defined and repeatable water stress conditions so that a large amount of genotypes can be evaluated efficiently (Ramirez and Kelly, 1998). Deviation of temperature of plant canopies in comparison to ambient temperature, also known as CTD (canopy temperature depression), has been recognized as an indicator of overall plant water status (Ehrler, 1972; Jackson et al., 1981; Blum et al., 1982; Idso, 1982) and used in such practical applications as evaluation of plant response to environmental stress (Jackson et al., 1981; Idso et al., 1984; Howell et al., 1986). High CTD has been used as a selection criterion to improve tolerance to drought and heat (Amani et al., 1996; Blum, 1996; Ayeneh et al., 2002; Karimizadeh and Mohammadi, 2011; Karimizadeh et al., 2012) and has been associated with yield increase among bread wheat cultivars at CIMMYT (Fischer et al., 1998). At the end of 1980s, CIMMYT began CTD measurements on different irrigated experiments in Northwest Mexico and it was found that phenotypic correlations of CTD with grain yield were occasionally positive (Reynolds et al., 1994; Fischer et al., 1998). Munjal and Rana (2003) have reported that cool canopy during grain filling period in wheat is an important physiological principle for high temperature stress tolerance.

Chlorophylls (Chl) are a dominant factor controlling leaf optical properties of healthy green vegetation and are thus an essential part of the photosynthetic process (Bahar, 2015). In general, chloroplasts occur more often towards the upper side of palisade cells, for this reason the upper leaf surface appears darker compared to the bottom surface side (Jensen, 2007). If optical methods for measuring leaf chlorophyll content are applied, index values (e.g. SPADvalue) are commonly used to specify the relative leaf chlorophyll content, but not absolute chlorophyll content or concentration (Richardson et al., 2002). Generally, nondestructive techniques to estimate chlorophyll content of vegetation are of significant importance to agricultural management operations, particularly in precision farming (Gitelson et al., 2003). The scientific interest was verified by Kaufman et al. (2010), showing that chlorophyll content is among the parameters with the highest frequency within investigations of agricultural hyper spectral studies. Those investigations are strongly dependent on quick, nondestructive and accurate in situ reference measurements.
The objective of the study was to determine the relationships of CTD and chlorophyll content with grain yield and yield components in twelve durum wheat genotypes in Gachsaran semi-warm condition of Iran.

\section{Materials and Methods}

\section{Plant material}

Field trials were conducted in 2014-2015 growing season at Gachsaran Agricultural Research Station situated at 710 meters altitude above sea level, with longitude $50^{\circ} 50^{\prime}$ East and latitude $30^{\circ} 20^{\prime}$ North, located in Southwestern Iran. Soil texture of experimental site is silty clay loam and 20 years average of rainfall was $431 \mathrm{~mm}$. Within the study, twelve durum wheat genotypes (Table 1) were planted in two sets (each set had 4 replicates) by a randomized complete block design, under two supplementary irrigation and rain-fed conditions (twice irrigation supplied for the supplemental irrigated set). Plots were sown at a seeding rate of 300 seeds $/ \mathrm{m}^{2}$ by Wintersteiger AG trial drilling machine on 6 December 2014. Plots contained six rows $(7.03 \mathrm{~m}$ long) with row spacing of $17.5 \mathrm{~cm}$. Fertilizers were applied as $80 \mathrm{~kg} \mathrm{ha}^{-1}$ of nitrogen and $80 \mathrm{~kg} \mathrm{ha}^{-1}$ of phosphorus (40.40.0 compose fertilizer) at planting time, whereas $80 \mathrm{~kg}$ $\mathrm{ha}^{-1}$ of nitrogen as ammonium nitrate (half of the top dressed fertilizer) was given at tillering and the other half was given at swollen stage. No disease was shown during growth period and weed control was made by chemical method (Topic and Granstar). After physiological maturity, plots were harvested by Wintersteiger AG trial thrasher/ harvester machine.

Regional climatic data during growth season (mean of November 2014 to June 2015) average monthly temperature and rainfall according to months are shown in Table 2. Total rain amount was of $351.6 \mathrm{~mm}$ in growing season. The rainfall from emergence of eighty percent of inflorescence stage to completing of 50 percent anthesis stage was very low for 33 days. Maximum air temperature at measurement dates (23 March and 6 April 2014-2015) was 24.8 and $29.4^{\circ} \mathrm{C}$ respectively. Average temperature was 21.3 and $27.6^{\circ} \mathrm{C}$ on the days of measurement in 2014-2015 respectively. Relative humidity percent were 53.5 and 58.2 on the same dates (Annual report, 2014-15). Twice irrigation for trial under supplementary irrigation condition at 14 March and 2 April in 2015 were conducted.

\section{Measurement of canopy temperature}

Canopy temperature depression (CTD) of each plot was measured with a hand-held infra-red thermometer (IRT) (Model 8866, JQA Instrument, Inc., Tokyo, Japan) at approximately $50 \mathrm{~cm}$ above the canopy. Four measurements per plot (two facing East and two facing West) were taken around noon and averaged to give one reading per plot. The CTD is reported here as the difference between air temperature ( $\mathrm{Ta}$ ) and canopy temperature $(\mathrm{Tc})$ with positive values when canopies were cooler than the air. Ssimilar to the method of Fischer et al. (1998), the data for each plot were the mean of four readings, taken from the same side of each plot at an angle of approximately $45^{\circ}$ to the horizontal in a range of directions such that they covered different regions of the plot and integrated many leaves. Also, measurements were at different periods, on 18 
March 2015 (Zadoks Growth Scale (ZGS) ZGS 54, emergence of fifty percent of inflorescence) and 25 April 2015 (ZGS 71 watery ripe, clear liquid) by using Zadoks et al. (1974).

\section{Measurement of chlorophyll content}

Measurements with the SPAD chlorophyll meter require no special environmental conditions and can be taken at any time, in any weather and at any developmental stage of plants. For the SPAD chlorophyll meter there is no special preparation apart from the calibration. Calibration is necessary whenever the meter is switched on. During calibration the two LEDs emit light sequentially without any sample leave in the measuring head. The received light is converted into electrical signals and the ratio of their intensities is calculated. Flag leaf chlorophyll content was measured at beginning of anthesis (ZGS 54; 19 March, 2015) and early milk stage (ZGS 73; 12 May, 2015) by using of a Minolta SPAD meter on 3 flag leaves per plot. Both were determined at the mid-point of each intact flag leaf from ten main stems in each genotype and recorded by chlorophyll meter in SPAD units.

\section{Data analysis}

Analysis of variance of grain yield, CTDs and CHLs measurements was performed by Genstat 12 statistical packed program. Correlations between traits were evaluated by MINITAB 14. Figure and tables were prepared by MINITAB 14 and excel software.

\section{Results}

The results of combined analyses of variance for grain yield, CTDs and CHLs measurements in supplementary irrigation and rain-fed conditions are shown in Table 3. Environment showed high significant difference at 0.01 probability level for all traits and for genotype showed high significant difference at 0.01 probability level for grain yield and non-significant difference for CTD1 and CHL2 (Table 3).

Genotype $\times$ environment interaction showed significant difference at 0.01 probability level in all traits accepted CTD1. Drought tolerant indices were calculated on the basis of grain yield of genotypes (Table 4). According to MP, GMP and STI indices, genotype G10 exhibited the most and genotype G6 the least relative tolerance, respectively. Based on MP and GMP, genotype G10 was found to be drought tolerant, while genotype G6 displayed the lowest amount of MP and GMP. Results showed a significant and positive correlation between TOL and YP, along with a significant and negative correlation between TOL and YS. There was a positive significant correlation between STI and YS, as well as between YP and MP indices (Table 5).

It was concluded that MP and STI discriminate tolerant genotypes under rain-fed conditions. A greater K1STI value was related to G5 and G8, indicating that these genotypes had a larger grain yield reduction under rain-fed condition as compared with their respective controls and higher

Table 1. Name and pedigree of durum wheat genotypes

\begin{tabular}{cc}
\hline Genotype code & Name and Pedigree \\
\hline G1 & Ter-1//Mrfl/Stj2 \\
G2 & Ammar-8 \\
G3 & Icajihan2 \\
G4 & Geromtel-1/Icasyr-1 \\
G5 & Arislahn-8//Bidral/Miki \\
G6 & Ouasloukos-1/5/Azn1/4/BEZAIZ-SHF//SD-19539/Waha/3/Gdr \\
G7 & Icasyr-1/3/Gcn//Stj/Mrb3 \\
G8 & Geruftel-2 \\
G9 & Aghrass1/3/Mrfl//Mrb16/Ru/Seri 34/2010-11 \\
G10 & Icasyr1/3/Bcr/Sbl5//T.urartu/Seri 34/2010-11 \\
G11 & Icarashal/Seri 33/2009-10 \\
G12 & Dehdasht \\
\hline
\end{tabular}

Table 2. Regional climatic data including average temperature and rainfall for 2014-2015 growth season

\begin{tabular}{ccc} 
Month & Average temperature & $\begin{array}{c}\text { Rainfall } \\
(\mathrm{mm})\end{array}$ \\
\hline October & $\left({ }^{\circ} \mathrm{C}\right)$ & 38.4 \\
\hline November & 24.0 & 57.4 \\
December & 15.6 & 62.8 \\
January & 13.2 & 56.9 \\
\hline February & 12.2 & 57.8 \\
\hline March & 14.2 & 57.8 \\
April & 15.9 & 39.2 \\
May & 22.6 & 29.7 \\
\hline June & 28.4 & 29.3 \\
\hline Total & 32.5 & 351.6 \\
\hline
\end{tabular}


578

drought sensitivity. Genotypes G7, G10 and G12 showed the highest amount of GOL.

The results indicated that there was a positive and significant correlation among YP and MP, GMP, SSI, $\mathrm{K}_{1} \mathrm{STI}$ and TOL indices and negative significant correlation between Ys and GOL index. Also, there was a positive and significant correlation among YS and GMP, STI, HM, $\mathrm{K}_{2} \mathrm{STI}$ and GOL indices. CTD values of ZGS 54 (CTD1) in durum wheat showed significant correlation with CTD2 (value of ZGS 71), chlorophyll content in anthesis (CHL1), YS, SSI, GOL and $\mathrm{k}_{2}$ STI indices (Table 6) in rain-fed condition. CTD1 in durum wheat showed significant correlation with CTD2, CHL1, CHL2, YP, TOL, MP, SSI and GOL indices in supplementary irrigation condition. CTD values of ZGS 71 showed significant correlation with CTD1, CHL1, YS, GOL and $\mathrm{k}_{2} \mathrm{STI}$ indices in rain-fed condition. CTD2 in durum wheat showed significant correlation with CTD1, CHL1, CHL2, YP, TOL, SSI and GOL indices in supplementary irrigation condition (Table 6).

Grain yield in rain-fed and supplementary irrigation conditions was taken into account in the present study, whereas CTDs, CHLs and drought indices replace it.

The correlation coefficients among the 13 indices are presented in Figs. 1 and 2 for rain-fed and supplementary irrigation conditions. According to the ATC, the length of the average place vector was adequate to select genotypes based on mean yield. The vector view of a biplot provides a summary of the interrelationships among the indices (Karimizadeh et al., 2016b). The biplot explained an adequate amount $(\geq 50 \%)$ of the total variation, therefore the correlation coefficient between any two indices can be seen as reliable. The biplot in Fig. 1 (rain-fed irrigation condition) and Fig. 2 (supplementary irrigation condition) explained 88.6 and $88.9 \%$ of the total variation, respectively and so these biplots can be used for extracting interrelationships among the indices.
The correlation coefficient between any two indices is estimated by the cosine of the angle between their vectors. Two indices are positively correlated if the angle between their vectors is $\left\langle 90^{\circ}\right.$, negatively correlated if the angle is $>$ $90^{\circ}$, independent if the angle is $90^{\circ}$. Also, indices with longer vectors are more responsive to the genotypes, while indices with shorter vectors are less responsive to the genotypes and those at the biplot origin are not responsive at all (Karimizadeh et al., 2013).

Coupling indices (TOL and SSI), (YS and GOL), (YP and $\mathrm{K}_{1} \mathrm{STI}$ ), (CTD1 and CTD2) had vectors with the least angle and showed the highest positive correlation with each other.

The results obtained from this biplot confirm the results of correlation shown in Tables 4 and 5. In supplemental irrigation condition, STI and GMP and average index vectors had the smallest angle with each other and therefore had a positive and high correlation with each other and with average index (Fig. 2). Similar to rain-fed condition, in supplementary irrigation condition, coupling indices (TOL and SSI), (YS and GOL), (YP and $\mathrm{K}_{1} \mathrm{STI}$ ), (CTD1 and CTD2) and (CHL1 and CHL2) had vectors with the least angle and therefore showed the highest positive correlation with each other. CTD values in supplementary irrigation condition in comparison to rain-fed condition increased especially in ZGS 54 stage (Fig. 3 and 4).

Cooler canopy temperature at heading and grain filling stages led to increasing in yield for each condition. The physiological basis of drought tolerance among durum wheat genotypes was associated with improved chlorophyll content rates from heading onwards (Fig. 5 and 6), as well as more leaf chlorophyll content during grain filling, greater weight of grain or thousand kernel weight.

The results obtained showed that CTD and chlorophyll content can be used for determining drought tolerant genotypes.

Table 3. Combined analysis of variance for grain yield, canopy temperature depression (CTD) and chlorophyll content (CHL) for both rain-fed and supplementary irrigation conditions

\begin{tabular}{|c|c|c|c|c|c|c|}
\hline Source & df & Grain yield mean square & $\begin{array}{c}\text { CTD } 1 \\
\text { mean square }\end{array}$ & $\begin{array}{c}\text { CTD } 2 \\
\text { mean square }\end{array}$ & $\begin{array}{c}\text { CHL } 1 \\
\text { mean square }\end{array}$ & $\begin{array}{c}\text { CHL 2 } \\
\text { mean square }\end{array}$ \\
\hline Environment & 1 & $52901746^{* *}$ & $56.43^{* *}$ & $30.94^{* *}$ & $1107.6^{* *}$ & $405.2^{* *}$ \\
\hline Error 1 & 6 & 1010965 & 0.967 & 0.754 & 316.6 & 207.0 \\
\hline Genotype & 11 & $1085328^{* *}$ & $0.257^{\mathrm{ns}}$ & $0.315^{*}$ & $61.08^{*}$ & $59.07^{\mathrm{ns}}$ \\
\hline $\mathrm{G} \times \mathrm{E}$ & 11 & $1525770^{* *}$ & $0.354^{\mathrm{ns}}$ & $0.558^{* *}$ & $97.04^{* *}$ & $99.05^{* *}$ \\
\hline Error 2 & 66 & 123040 & 0.215 & 0.150 & 32.91 & 40.64 \\
\hline $\mathrm{CV} \%$ & - & 9.3 & 10.1 & 10.2 & 8.4 & 11.5 \\
\hline $\mathrm{R}^{2} \%$ & - & 79.2 & 82.8 & 81.9 & 68.6 & 55.8 \\
\hline
\end{tabular}

Table 4. Drought tolerance indices and two first principal components of 12 durum wheat genotypes under supplementary and rain-fed conditions

\begin{tabular}{|c|c|c|c|c|c|c|c|c|c|c|c|}
\hline $\begin{array}{c}\text { Genotypes } \\
\text { Code }\end{array}$ & $\begin{array}{c}\mathrm{YS} \\
(\mathrm{kg} / \mathrm{ha})\end{array}$ & $\begin{array}{c}\mathrm{YP} \\
(\mathrm{kg} / \mathrm{ha})\end{array}$ & TOL & MP & $\begin{array}{c}\text { GMP } \\
(?)\end{array}$ & SSI & STI & $\mathrm{HM}$ & $\mathrm{K}_{1} \mathrm{STI}$ & $\mathrm{K}_{2} \mathrm{STI}$ & GOL \\
\hline G1 & 2,976 & 4,576 & 1,600 & 3,776 & 3,690 & 1.162 & 0.755 & 3607 & 1.16 & 1.00 & 4.7 \\
\hline G2 & 2,818 & 3,844 & 1,025 & 3,331 & 3,291 & 0.886 & 0.601 & 3252 & 0.82 & 0.90 & 6.5 \\
\hline G3 & 2,946 & 4,368 & 1,422 & 3,657 & 3,587 & 1.082 & 0.713 & 3519 & 1.06 & 0.98 & 5.1 \\
\hline G4 & 3,226 & 4,248 & 1,023 & 3,737 & 3,702 & 0.800 & 0.760 & 3667 & 1.00 & 1.18 & 7.3 \\
\hline G5 & 2,640 & 4,868 & 2,228 & 3,754 & 3,585 & 1.521 & 0.713 & 3424 & 1.31 & 0.79 & 3.4 \\
\hline G6 & 2,690 & 3,910 & 1,220 & 3,300 & 3,243 & 1.037 & 0.583 & 3187 & 0.85 & 0.82 & 5.4 \\
\hline G7 & 3,179 & 3,633 & 453 & 3,406 & 3,399 & 0.415 & 0.640 & 3391 & 0.73 & 1.15 & 15 \\
\hline G8 & 2,694 & 4,822 & 2,128 & 3,758 & 3,604 & 1.466 & 0.720 & 3457 & 1.29 & 0.82 & 3.5 \\
\hline G9 & 3,112 & 4,377 & 1,265 & 3,744 & 3,690 & 0.961 & 0.755 & 3637 & 1.06 & 1.10 & 5.9 \\
\hline G10 & 3,389 & 4,245 & 856 & 3,817 & 3,793 & 0.670 & 0.798 & 3769 & 1.00 & 1.30 & 8.9 \\
\hline G11 & 2,926 & 4,220 & 1,294 & 3,573 & 3,514 & 1.019 & 0.685 & 3456 & 0.99 & 0.97 & 5.5 \\
\hline G12 & 3,027 & 3,852 & 825 & 3,440 & 3,415 & 0.712 & 0.646 & 3390 & 0.82 & 1.04 & 8.3 \\
\hline
\end{tabular}


Table 5. Correlation coefficients between the calculated drought tolerance indices

\begin{tabular}{|c|c|c|c|c|c|c|c|c|c|c|c|}
\hline $\begin{array}{l}\text { Genotypes } \\
\text { Code }\end{array}$ & YS & $\mathrm{YP}$ & TOL & MP & GMP & SSI & STI & HM & $\mathrm{K}_{1} \mathrm{STI}$ & $\mathrm{K}_{2} \mathrm{STI}$ & GOL \\
\hline YS & 1 & & & & & & & & & & \\
\hline YP & -0.273 & 1 & & & & & & & & & \\
\hline TOL & $-0.678^{*}$ & $0.839^{* *}$ & 1 & & & & & & & & \\
\hline $\mathrm{MP}$ & 0.245 & $0.769^{* *}$ & 0.434 & 1 & & & & & & & \\
\hline GMP & $0.553^{*}$ & $0.606^{*}$ & 0.172 & $0.879^{* *}$ & 1 & & & & & & \\
\hline SSI & $-0.776^{* *}$ & $0.776^{* *}$ & $0.972^{* *}$ & 0.301 & 0.028 & 1 & & & & & \\
\hline STI & $0.537^{*}$ & $0.621^{*}$ & 0.182 & $0.891^{* *}$ & $0.998^{* *}$ & 0.039 & 1 & & & & \\
\hline $\mathrm{HM}$ & $0.622^{*}$ & $0.517^{*}$ & 0.112 & $0.804^{* *}$ & $0.977^{* *}$ & -0.049 & $0.968^{* *}$ & 1 & & & \\
\hline KISTI & -0.295 & $0.995^{* *}$ & $0.858^{* *}$ & $0.777^{* *}$ & $0.597^{*}$ & $0.791^{* *}$ & $0.610^{*}$ & 0.513 & 1 & & \\
\hline $\mathrm{K}_{2} \mathrm{STI}$ & $0.998^{* *}$ & -0.298 & $-0.697^{* *}$ & 0.214 & 0.530 & $-0.788^{* *}$ & 0.513 & $0.602^{*}$ & -0.320 & 1 & \\
\hline GOL & $0.776^{* *}$ & $-0.776^{* *}$ & $-0.972^{* *}$ & -0.301 & -0.028 & $-1.000^{* *}$ & -0.039 & 0.049 & $-0.791^{* *}$ & $0.788^{* *}$ & 1 \\
\hline
\end{tabular}

Table 6. Correlation coefficients among CTDs and CHLs values, grain yield and drought indices in durum wheat genotypes in rain-fed and supplemental irrigation conditions

\begin{tabular}{|c|c|c|c|c|c|c|c|c|c|c|c|c|c|}
\hline CTDs/CHLs & YS & YP & $\mathrm{TOL}$ & MP & SSI & STI & $\mathrm{HM}$ & $\mathrm{K}_{2} \mathrm{STI}$ & $\overline{\mathrm{GOL}}$ & $\mathrm{CTDl}^{\dagger}$ & CTD2 & $\mathrm{CHLl}^{\dagger+}$ & CHL2 \\
\hline \multicolumn{14}{|c|}{ Rain-fed condition } \\
\hline CTD1(ZGS 54) & $0.65^{*}$ & -0.29 & -0.48 & -0.01 & $-0.61^{*}$ & 0.27 & 0.38 & $0.65^{*}$ & $0.61^{*}$ & 1 & $0.78^{* *}$ & $0.79^{* *}$ & 0.34 \\
\hline CTD2(ZGS 71) & $0.57^{*}$ & -0.33 & -0.45 & 0.07 & $-0.58^{*}$ & 0.25 & 0.29 & $0.57^{*}$ & $0.58^{*}$ & $0.78^{* *}$ & 1 & $0.93^{* *}$ & 0.52 \\
\hline CHLI(ZGS 54) & $0.70^{*}$ & -0.44 & $-0.63^{*}$ & 0.03 & $-0.75^{* *}$ & 0.19 & 0.24 & $0.69^{*}$ & $0.75^{* *}$ & $0.79^{* *}$ & $0.93^{* *}$ & 1 & $0.66^{*}$ \\
\hline CHL2(ZGS 73) & $0.54^{*}$ & $-0.59^{*}$ & $-0.64^{*}$ & -0.15 & $-0.67^{*}$ & -0.08 & -0.05 & $0.54^{*}$ & $0.67^{*}$ & 0.34 & $0.52^{*}$ & $0.66^{*}$ & 1 \\
\hline \multicolumn{14}{|c|}{ Supplemental irrigation } \\
\hline CTD1(ZGS 54) & -0.26 & $0.65^{*}$ & $0.63^{*}$ & $0.53^{*}$ & $0.51^{*}$ & 0.37 & 0.31 & -0.29 & $-0.51^{*}$ & 1 & $0.89^{* *}$ & $0.95^{* *}$ & $0.94^{* *}$ \\
\hline CTD2(ZGS 71) & -0.29 & $0.64^{*}$ & $0.65^{*}$ & 0.41 & $0.56^{*}$ & 0.25 & 0.20 & -0.32 & $-0.56^{*}$ & $0.89^{* *}$ & 1 & $0.86^{* *}$ & $0.80^{* *}$ \\
\hline CHLl(ZGS 54) & -0.26 & $0.62^{*}$ & $0.60^{*}$ & $0.57^{*}$ & 0.46 & 0.36 & 0.28 & -0.29 & -0.46 & $0.95^{* *}$ & $0.86^{* *}$ & 1 & $0.85^{* *}$ \\
\hline CHL2(ZGS 73) & -0.21 & $0.55^{*}$ & $0.58^{*}$ & 0.44 & 0.45 & 0.32 & 0.31 & -0.22 & -0.45 & $0.94^{* *}$ & $0.80^{* *}$ & $0.85^{* *}$ & 1 \\
\hline
\end{tabular}

${ }^{*} \mathrm{P}<0.05,{ }^{* *} \mathrm{P}<0.01{ }^{\dagger}$ Canopy temperature depression in ZGS 54 and ZGS 71 , respectively

${ }^{+\dagger}$ Chlorophyll content in heading and grain filling stages, respectively.

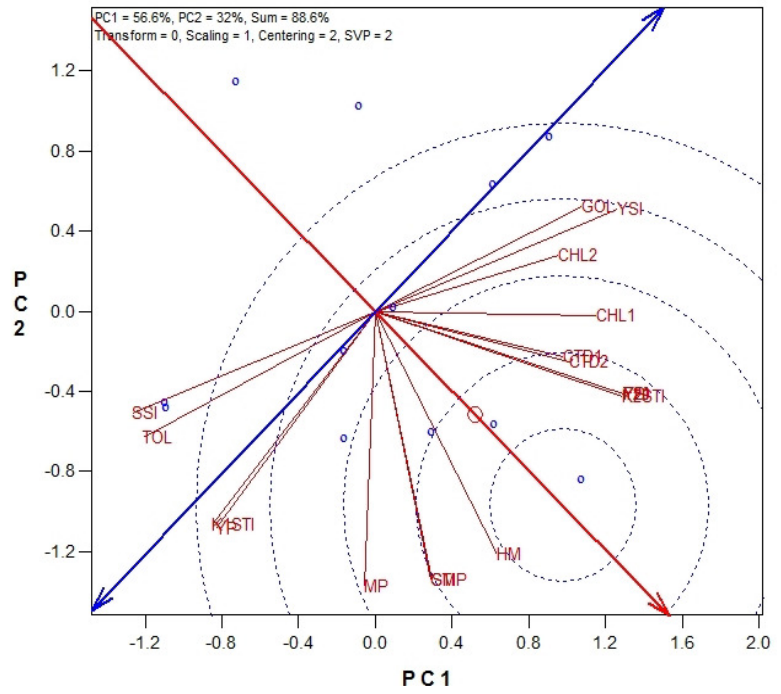

Fig. 1. Biplot of principal component analysis of physiological traits, grain yield and drought tolerance indices in rain-fed condition

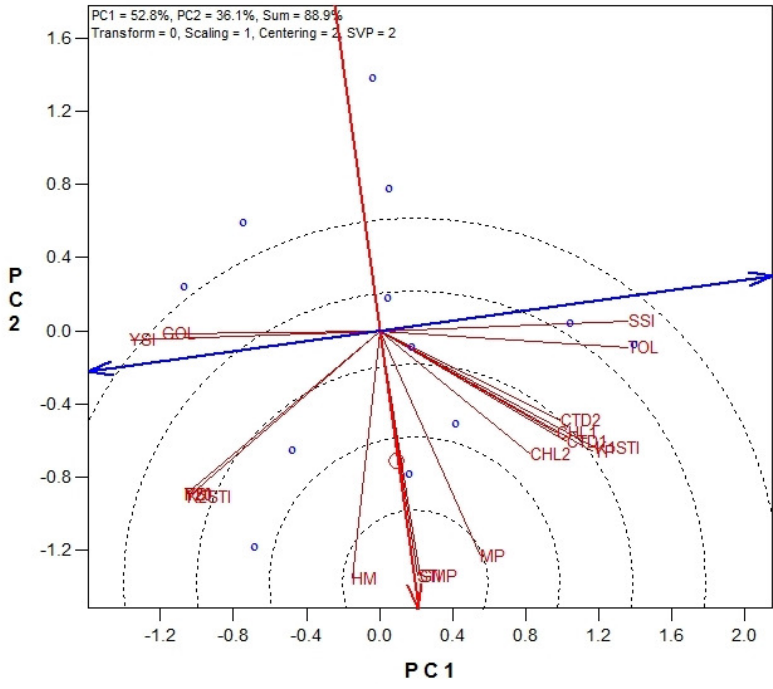

Fig. 2. Biplot of principal component analysis of physiological traits, grain yield and drought tolerance indices in supplemental irrigation condition 


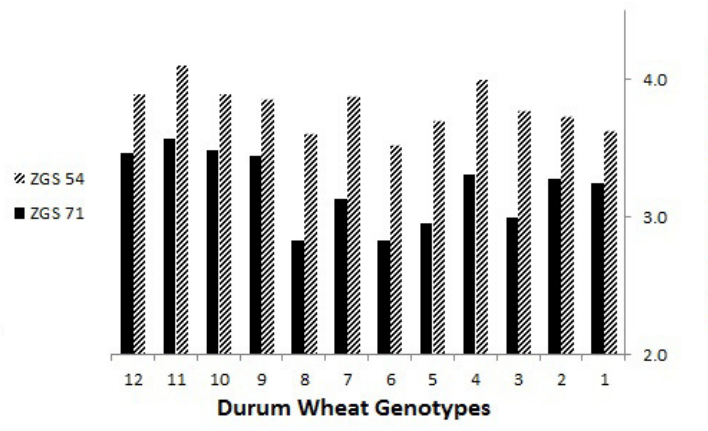

Fig. 3. Canopy temperature depression values of durum wheat genotypes in rain-fed condition

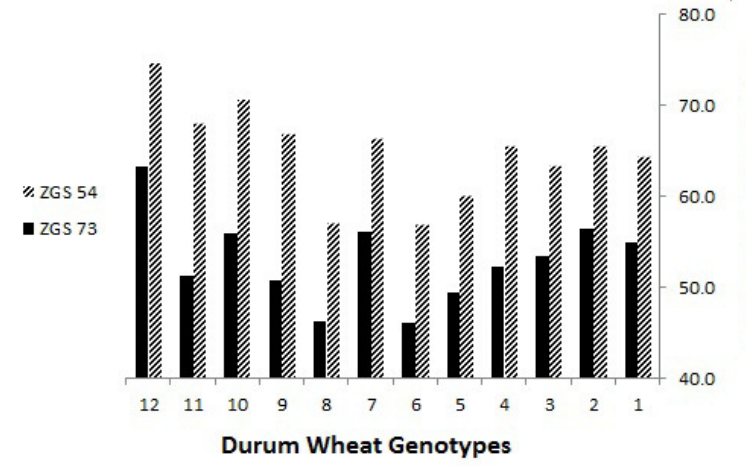

Fig. 5. Canopy temperature depression values of durum wheat genotypes in rain-fed condition

\section{Discussion}

The results obtained hereby suggested that high potential performance under supplementary conditions does not necessarily result in improved performance under rain-fed conditions. Thus, indirect selection for a drought prone environment based on the results of best (supplementary) conditions will not be efficient. These results are in agreement with those of Bruckner and Frohberg (1987), Karimizadeh et al. (2011, 2012) saying that wheat by low yield potential was more productive under rain-fed conditions.

Mohammadi and Abdolahi (2017) reported that cultivars producing high yield in both drought and well watered conditions can be identified by STI, GMP and MP values. Pireivatlou et al. (2010) also pointed that STI can be a reliable index for selecting high yielding genotypes. A greater TOL value was related to G5 and G8 hereby studied, indicating that these genotypes had a larger grain yield reduction under rain-fed condition as compared with their controls and higher drought sensitivity. Genotypes G5, G8 and G1 showed the highest amount of SSI. Greater SSI value was confirmed to be an adverse reason for drought tolerance. Fernandez (1992) stated that selection based on TOL favours genotypes with low yield potential under nonstress conditions and high yield under stress conditions. SSI is a better index than TOL for selecting genotypes under stress condition. Greater GOL value was confirmed to be a good reason for drought tolerance (Karimizadeh et al., 2014). Rosielle and Hamblin (1981) suggested that a low

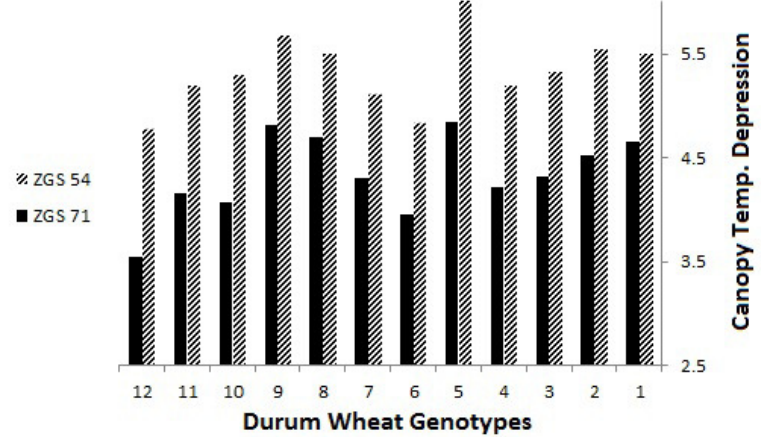

Fig. 4. Canopy temperature depression values of durum wheat genotypes in supplementary irrigation condition

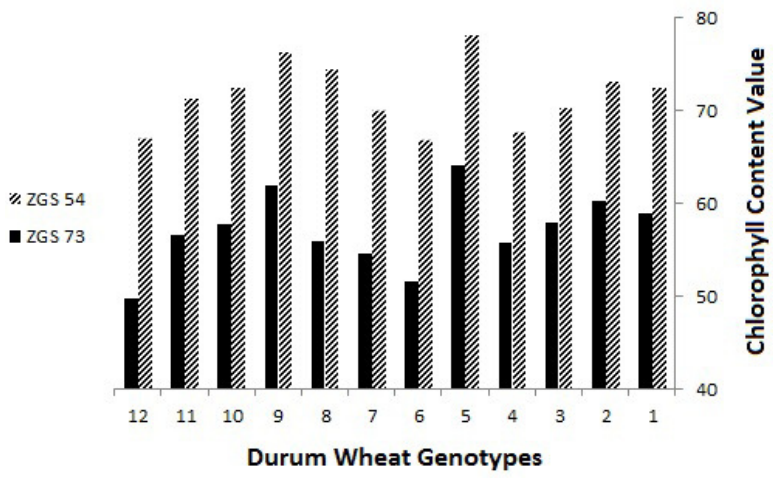

Fig. 6. Canopy temperature depression values of durum wheat genotypes in supplementary irrigation condition

value of TOL is associated with low sensitivity to stress and selection solely based on this index potentially leads to high yielding genotypes in stress conditions. Naghavi et al. (2017) showed that among drought tolerance indices, MP, GMP, STI, YI, SSPI, K1STI and K2STI can be used as the most suitable indicators for screening drought tolerant cultivars because had highest correlation with Yp and Ys and this tolerant correlation had positive correlation together. It is suggested that selection based on TOL will result in reduced yield under well-watered conditions. Similar results were reported by Clarke et al. (1992).

In the present study, yield under irrigation was about $43 \%$ higher than yield under rain-fed. Since MP is a mean production under both rain-fed and supplementary irrigation conditions, it will be correlated with YP, GMP, STI, HM and $\mathrm{K}_{1} S T I$ indices. This result is similar to the results of Fallahi et al. (2011), Khaksar et al. (2014), Molla Heidary Bafghi et al. (2017). The observed relations are consistent with those reported by Farshadfar and Sutka (2002) in maize, Golabadi et al. (2006), Talebi et al. (2009) and Yaghotipour et al. (2017) in durum and bread wheat.

Selection based on a combine of indices may give a more useful criterion for improving drought tolerance of wheat, but the study of correlation coefficients are useful in finding the degree of overall linear association between any two attributes. Thus, a better approach than a correlation analysis such as biplot is needed to find the superior genotypes for both rain-fed and supplementary irrigation environments. In GGE biplot methodology, the yield and stability of the genotypes were examined by an average tester 
coordinate (ATC). The mean yield of the genotypes is estimated by their projections on the ATC $\mathrm{x}$ - axis. The average place, as the virtual place, is showed by a circle and indicates the positive end of the ATC $\mathrm{x}$ - axis. According to Yan (2002), discriminating ability and representatives are important properties of a test place which an ideal place should be highly differentiating of the tested genotypes and at the same time representative of the target locations. In this research, CTD1, CTD2, K2STI and HM had the smallest angle with each other and had a positive and high correlation among them and with average index in rain-fed condition. The results obtained from the biplot confirm the results of correlation Tables 5 and 6. CTD values have been observed such as 4.1 and $3.6^{\circ} \mathrm{C}$ in G11 at heading and grain filling periods in rain-fed condition. It was understood that this genotype have cooler plant canopy than the other cultivars. Also, Barma et al. (1997) showed that CTD values could have been changed between -2.4 and $-5.5{ }^{\circ} \mathrm{C}$ sometimes.

The effectiveness of selection indices depends on the stress severity supporting the idea that only under moderate stress conditions, potential yield greatly influences yield under stress (Blum 1996; Panthuwan et al., 2002). Two primary schools of thought have influenced plant breeders who target their germplasm to drought-prone areas. The first of these philosophies states that high advice responsiveness and inherently high yielding potential, combined with stress- adaptive traits, will improve performance in drought-affected environments (Van Ginkel et al., 1995; Richards 1996; Rajaram and Van Ginkle 2001; Betran et al., 2003). The breeders who advocate selection in favourable environments follow this philosophy. Producers, therefore, prefer cultivars that produce high yields when water is not so limiting, but suffer a minimum loss during drought seasons (Nasir Ud-Din $e t$ al., 1992). The second is the belief that progress in yield and adaptation in drought- affected environments can be achieved only by selection under the prevailing conditions found in target environments (Ceccarelli, 1987; Ceccarelli and Grando, 1991; Rathjen, 1994). The theoretical framework to this issue has been provided by Falconer (1952) who wrote "yield in low and high yielding environments can be considered as separate traits which are not necessarily maximized by same sets of alleles".

\section{Conclusions}

The results of calculated gain from indirect selection in drought stress environment would improve yield in such conditions better than selection from non-moisture stress environment. Wheat breeders should, therefore, take into account the stress severity of the environment when choosing an index. Estimating yield from a small number of short-term CTD measurements seems much more dubious, however, since short-term CTD and transpiration rate are related to temporally variable environmental properties including irradiance, air temperature, wind speed and vapour pressure deficit. Among different resistance and tolerance indices, were evaluated those that might have high correlation with grain yield under stress and non-stress condition, indicating more suitability of these indices for selection of resistant genotype. By screening drought tolerant cultivars using biplot method, genotypes G10 and G4 were noted as the most drought tolerant. Therefore, they are recommended to be used as parents for improvement of drought tolerance in other cultivars.

\section{Acknowledgements}

The authors wish to thank Dr. Wei-Kai Yan (Eastern Cereal Oilseed Research Center of Agriculture and AgriFood Canada) for making available a time-limited version of GGEbiplot.

\section{References}

Amani I, Fischer RA, Reynolds MP (1996). Canopy temperature depression association with yield of irrigated spring wheat cultivars in hot climate. Journal of Agronomy Crop Science 176(2):119-129.

Annual Report (2014). Monthly weather reports of meteorology regional headship, Gachsaran Agricultural Weather Station, Iran.

Annual Report (2015). Monthly weather reports of meteorology regional headship, Gachsaran agricultural weather station, Iran.

Ayeneh A, Van Ginkel M, Reynolds MP, Ammar K (2002). Comparison of leaf, spike, peduncle, and canopy temperature depression in wheat under heat stress. Field Crops Research 79(2-3):173-184.

Bahar B (2015). Relationships among flag leaf chlorophyll content, agronomical traits, and some physiological traits of winter wheat genotypes. Dicle University Institute of Natural and Applied Science Journal 4(1):1-5.

Barma NC, Rahman M, Amin R, Sarker ZI, Meisner C, Razzaque MA (1997). Summary of data from Bangladesh. In: Reynolds MP, Nagarajan S, Razzaque MA, Ageeb OAA (Eds). Using canopy temperature depression to select for yield potential of wheat in heatstressed environments. Wheat Prog Special Rep. 42. Mexico, CIMMYT,DF21-22.

Beltrano J, Ronco MG (2008). Improved tolerance of wheat plants (Triticum aestivum L.) to drought stress and rewatering by the arbuscular mycorrhizal fungus Glomus claroideum: effect on growth and cell membrane stability. Brazilian Journal of Plant Physiology 20(1):2937.

Betran FJ, Beck D, Banziger M, Edmeades GO (2003). Genetic analysis of inbred and hybrid grain yield under stress and non-stress environments in tropical maize. Crop Science 43(3):807-817.

Blum A, Mayer J, Gozlan G (1982). Infrared thermal sensing of plant canopies as a screening technique for dehydration avoidance in wheat. Field Crops Research 5:137-146.

Blum A (1988). Plant breeding for stress environments. CRC Press, Boca Raton, Florida, USA.

Blum A (1996). Crop responses to drought and the interpretation of adaptation. Plant Growth Regulation 20:135-148.

Bouslama M, Schapaugh WT (1984). Stress tolerance in soybean. Part 1: evaluation of three screening techniques for heat and drought tolerance. Crop Science 24(5):933-937.

Bruckner PL, Frohberg RC (1987). Stress tolerance and adaptation in spring wheat. CropScience 27(1):31-36. 
582

Ceccarelli S (1987). Yield potential and drought tolerance of segregating populations of barley in contrasting environments. Euphytica 36(1):265-273.

Ceccarelli S, Grando S (1991). Selection environment and environmental sensitivity in barley. Euphytica 57(2):157-167.

Clarke JM, De Pauw RM, Townley-Smith TM (1992). Evaluation of methods for quantification of drought tolerance in wheat. Crop Science 32:728-732.

Ehrler WL (1972). Cotton leaf temperatures as related to soil water depletion and meteorological factors 1. Agronomy Journal 65(3):404 409.

Falconer DS (1952). The problem of environment and selection. American Naturalist 86:293-298.

Fallahi HA, Jafarby JA, Seyedi F (2011). Evaluation of drought tolerance in durum wheat genotypes using drought tolerance indices. Seed and Plant Breeding27(1):15-22.

Farshadfar E, Sutka J (2002). Multivariate analysis of drought tolerance in wheat substitution lines. Cereal Research Communication 31:33-40.

Farshadfar E, Sutka J (2003). Screening drought tolerance criteria in maize. Acta Agronomy Hungary 50(4):411-416.

Fernandez GCJ (1992). Effective selection criteria for assessing stress tolerance. In: Kuo CG (Ed). Proceedings of the International Symposium on Adaptation of Vegetables and other Food Crops in Temperature and WaterStress, Taiwan.

Fischer RA, Maurer R(1978). Drought resistance in spring wheat cultivars. I. Grain yield responses. Australian Journal of Agricultural Research 29(5):897-912.

Fischer RA, Rees D, Sayre KD, Lu ZM, Condon AG, Larque Saavedra A (1998). Wheat yield progress associated with higher stomatal conductance and photosynthetic rate, and cooler canopies. Crop Science 38(6):1467-1475.

Food and Agricultural Organization (FAO) (2015). FAO statistical yearbook. Part 3. Trends in the crop sector.FAO, Rome.

Gitelson AA, Gritz Y, Merzlyak MN (2003). Relationships between leaf chlorophyll content and spectral reflectance and algorithms for nondestructive chlorophyll assessment in higher plant leaves. Journal of Plant Physiology 160(3):271-282.

Golabadi M, Arzani A, Maibody SAM (2006). Assessment of drought tolerance in segregating populations in durum wheat. African Journal of Agricultural Research 1(5):162-171.

Guttieri MJ, Stark JC, Brien K, Souza E (2001). Relative sensitivity of spring wheat grain yield and quality parameters to moisture deficit. Crop Science 41(2):327-335.

Howell TA, Musick JT, Talk JA (1986). Canopy temperature of irrigated winter wheat. Transactions of the ASAE 29(6):1692-1699.

Idso SB (1982). Non-water-stressed baseline: a key to measuring and interpreting plant water stress. Agriculture and Forestry Meteorology 27(1-2):59-70.

Idso SB, Reginato RJ, Clawson KL, Anderson MG (1984). On the stability of non-water-stressed baselines. Agriculture and Forestry Meteorology 32:177-182.

Jackson RD, Idso SB, Reginato RJ, Pinter PJ (1981). Canopy temperature as acrop water stress index. Water Resources Research 17:1133-1138.
Jensen JR (2007). Remote sensing of the environment: an earth resource perspective. Prentice Hall series in Geographic Information Science. Edited2. Auflage. Pearson Prentice Hall. Upper Saddle River, NJ.

Karimizadeh R, Mohammadi M(2011). Association of canopy temperature depression with yield of durum wheat genotypes under supplementary irrigation and rain-fed conditions. Australian Journal of Crop Science 5(2):138-146.

Karimizadeh R, Mohammadi M, Sabaghnia N, Shefazadeh MK (2012). Using Huehn's nonparametric stability statistics to investigate genotype? Environment Interaction. Notulae Botanicae Horti Agrobotanici ClujNapoca 40(1):293-301.

Karimizadeh R, Sharifi P, Mohammadi M (2012). Correlation and path coefficient analysis of grain yield and yield components in durum wheat under two irrigated and rain fed condition. International Journal of Agriculture 2(3):277-283.

Karimizadeh R, Mohammad M, Sabahgni N, Mahmoodi AE, Roustami B, Seyyedi F, Akbari F (2013). GGE biplot analysis of yield stability in multi-environment trials of lentil genotypes under rain-fed condition. Notulae Botanicae Horti Agrobotanici Cluj-Napoca 5(2):256-262.

Karimizadeh R, Yousefi azar M, Mohammadi M (2014). Evaluation of durum wheat genotypes in rainfed and supplemental irrigation conditions in Gachsaran region of Iran. Seed and Plant Breeding 29(4):505-522.

Karimizadeh R, Asghari A, Chinipardaz R, Sofalian O, Ghaffari AA (2016a). Determining yield stability and model selection by AMMI method in rain-fed durum wheat genotypes. Turkish Journal of Field Crops 21(2):174183.

Karimizadeh R, Asghari A, Chinipardaz R, Sofalian O, Ghaffari AA (2016b). Application of GGE biplot analysis to evaluate grain yield stability of rainfed spring durum wheat genotypes and test locations by climatic factors in Iran. Crop Breeding Journal 6(2):41-49.

Kaufmann H, Segl K, Itzerott S, Bach H, Wagner A, Hill J, Heim B, Oppermann K, Heldens W, Stein E, Müller A, van der Linden S, Leito PJ, Rabe A, Hostert P (2010). Hyper spectral algorithms: report in the frame of EnMAP preparation activities, (Scientific Technical Report; 10/08), Potsdam: Deutsches GeoForschungsZentrum GFZpp 268.

Khaksar N, Farshadfar E, Mohammadi R (2014). Evaluation of durum wheat advanced genotypes based on drought tolerance indices. Cereal Research 3(4):267-279.

Mohammadi R, Abdulahi A (2017). Evaluation of durum wheat genotypes based on drought tolerance indices under different levels of drought stress. Journal of Agricultural Science 62(1):1-14.

Molla Heydari Bafghi R, Baghizadeh A, Mohammadinezhad G (2017). Evaluation of salinity and drought stresses tolerance in wheat genotypes using tolerance indices. Journal ofCrop Breeding 23(9):27-34.

Moosavi SS, Yazdi Samadi B, Naghavi MR, Zali AA, Dashti H, Pourshahbazi A (2008). Introduction of new indices to identify relative drought tolerance and resistance in wheat genotypes. Desert 12(2):165178.

Munjal R, Rana RK (2003). Evaluation of Physiological traits in wheat (Triticum aestivum L.) for terminal high temperature tolerance. Proceedings of the tenth international wheat genetics symposium. Italy. Classical and Molecular Breeding2(3):804-805. 
Naghavi MR, Pour Aboughadareh A, Khalili M (2017). Evaluation of drought tolerance indices for screening some of Corn (Zea mays L.) cultivars under environmental conditions. Notulae Botanicae Horti Agrobotanici Cluj-Napoca 5(3):388-393.

Nasir Ud-Din Carver BF, Clutte AC (1992). Genetic analysis and selection for wheat yield in drought-stressed and irrigated environments. Euphytica 62(2):89-96.

Panthuwan G, Fokai S, Cooper M, Rajatasereekul S, O’Toole JC (2002). Yield response of rice (Oryza sativa $\mathrm{L}$ ) genotypes to different types of drought under rain-fed lowlands. Part 1: grain yield and yield components. Field Crops Research 73(2-3):153-168.

Pireivatlou AM, Dehdar Masjedlou B, Aliyev RT (2010). Evaluation of yield potential and stress adaptive trait in wheat genotypes under post anthesis drought stress conditions. African Journal of Agricultural Research 5(20):2829-2836.

Rajaram S, Van Ginkle M (2001). 50 years of international wheat breeding in Mexico. In: Bonjean AP, Angus WJ (Eds), The World Wheat Book, A History of Wheat Breeding, Lavoisier Publishing, Paris, France pp 579-604.

Ramirez P, KellyJD (1998). Traits related to drought tolerance in common bean. Euphytica 99(2):127-136.

Rathjen AJ (1994). The biological basis of genotype-environment interaction, In: Proceedings of the seventh assembly of the wheat breeding society of Australia. Adelaide, Australia.

Reynolds MP, Balota M, Delgado MIB, Amani I, Fischer RA (1994). Physiological and morphological traits associated with spring wheat yield under hot irrigated conditions. Australian Journal of Plant Physiology 21(6):717-730.
Richards RA (1996). Defining selection criteria to improve yield under drought. Plant Growth Regulation 20(2):157-166.

Richardson RA, Rebetze GJ, Condon AG, Herwaarden AF (2002). Breedingopportunities for increasing the efficiency of water use and crop yield in temperate cereals. CropScience 42(1):111-121.

Rosielle AA, Hamblin J (1981). Theoretical aspects of selection for yield in stress and non-stress environment. Crop Science 21(6):943-946.

Talebi R, Fayaz F, Naji AM (2009). Effective selection criteria for assessing drought stress tolerance in durum wheat (Triticum durum desf.). Genetic and Applied Plant Physiology 35(1-2):6467.

Van Ginkel M, Calhoun DS, Gebeyehu G, Miranda A, Tian-You C, Wanjura DF, Upchurch DR, Mahan JR (1995). Control of irrigation scheduling using temperature-time thresholds. Transactions of the ASAE38(2):403-409.

Yaghootipor A, Farshadfar E, Saeedi M (2017). Evaluation of bread wheat genotypes for drought tolerance by using Suitable combination method. Environmental Stresses in CropScience 10(2):247-256.

Yan W (2002). Singular value partitioning in biplot analysis of multienvironment trial data. Agriculture Journal 94(5):990-996.

Zadoks JC, Chang TT, Konzak CF (1974). A decimal code for growth stages of cereals. Weed Research 14(6):415-421. 